OPEN ACCESS

Edited by:

Carol Seger

Colorado State University, USA

Reviewed by:

Tyler Davis,

Texas Tech University, USA

Philip Kragel,

University of Colorado Boulder, USA

*Correspondence:

Merel Kindt

m.kindt@uva.n

Received: 12 November 2015 Accepted: 29 April 2016

Published: 27 May 2016

Citation:

Visser RM, Haver P, ZwitserRJ, Scholte HS and KindtM (2016) First Steps in Using Multi-Voxel Pattern

Analysis to Disentangle Neural Processes Underlying Generalization of Spider Fear.

Front. Hum. Neurosci. 10:222. doi: 10.3389/fnhum.2016.00222

\section{First Steps in Using Multi-Voxel Pattern Analysis to Disentangle Neural Processes Underlying Generalization of Spider Fear}

\author{
Renée M. Visser ${ }^{1,2,3}$, Pia Haver ${ }^{1}$, Robert J. Zwitser ${ }^{4}$, H. Steven Scholte2,5 and \\ Merel Kindt'1,2*
}

${ }^{1}$ Department of Clinical Psychology, University of Amsterdam, Amsterdam, Netherlands, ${ }^{2}$ Amsterdam Brain and Cognition, University of Amsterdam, Amsterdam, Netherlands, ${ }^{3}$ Medical Research Council - Cognition and Brain Sciences Unit, Cambridge, UK, ${ }^{4}$ Department of Psychological Methods, University of Amsterdam, Amsterdam, Netherlands, ${ }^{5}$ Department of Brain and Cognition, University of Amsterdam, Amsterdam, Netherlands

A core symptom of anxiety disorders is the tendency to interpret ambiguous information as threatening. Using electroencephalography and blood oxygenation level dependent magnetic resonance imaging (BOLD-MRI), several studies have begun to elucidate brain processes involved in fear-related perceptual biases, but thus far mainly found evidence for general hypervigilance in high fearful individuals. Recently, multi-voxel pattern analysis (MVPA) has become popular for decoding cognitive states from distributed patterns of neural activation. Here, we used this technique to assess whether biased fear generalization, characteristic of clinical fear, is already present during the initial perception and categorization of a stimulus, or emerges during the subsequent interpretation of a stimulus. Individuals with low spider fear $(n=20)$ and high spider fear $(n=18)$ underwent functional MRI scanning while viewing series of schematic flowers morphing to spiders. In line with previous studies, individuals with high fear of spiders were behaviorally more likely to classify ambiguous morphs as spiders than individuals with low fear of spiders. Univariate analyses of BOLD-MRI data revealed stronger activation toward spider pictures in high fearful individuals compared to low fearful individuals in numerous areas. Yet, neither average activation, nor support vector machine classification (i.e., a form of MVPA) matched the behavioral results - i.e., a biased response toward ambiguous stimuli - in any of the regions of interest. This may point to limitations of the current design, and to challenges associated with classifying emotional and neutral stimuli in groups that differ in their judgment of emotionality. Improvements for future research are suggested.

Keywords: spider fear, multi-voxel pattern analysis (MVPA), fear generalization, fMRI, support vector machine, interpretation bias

\section{INTRODUCTION}

The ability to recognize threatening stimuli clearly increases the chances of survival. Given that a known threat can take many forms, it is also adaptive to be cautious with other exemplars of the same semantic category that may predict a similar aversive outcome (Mineka, 1992). Stimulus generalization -a learning mechanism whereby conditioned responses extend to a range of stimuli 
resembling the original conditioned stimuli (Pavlov, 1927) enables a fast response to novel potentially threatening stimuli. Yet, it can turn into maladaptive behavior when non-threatening stimuli or contexts are inappropriately treated as harmful. Here, we will refer to this phenomenon as 'overgeneralization of fear' or 'maladaptive fear generalization.' The way we use the term 'fear' here includes both physiological and behavioral responses to threat, as well as the subjective experience of fear (but see for an alternative use of the term 'fear' LeDoux, 2014).

Maladaptive fear generalization is a characteristic of anxiety disorders and post-traumatic stress disorder (Lissek et al., 2005, 2014; Mineka and Zinbarg, 2006; Kong et al., 2014; Bishop et al., 2015) and may even play a causal role in these disorders (Mathews and MacLeod, 2002; Wilson et al., 2006). For example, while in spider phobia fear responses to real spiders may be debilitating in itself, fear responses to stimuli that more or less resemble the object of fear (e.g., a piece of dust) may interfere most with daily functioning as phobic individuals find themselves in a permanent state of hypervigilance, avoiding many 'safe' situations (e.g., not eating tomatoes as their insides resemble the legs of a spider). Clarifying which processes enhance fear generalization will ultimately help to answer the fundamental question of why and how people differ in their disposition to develop maladaptive fears.

Based on decades of animal conditioning research that focused on the perceptual similarity and discriminability of threatening stimuli, it has been implicitly assumed that overgeneralization of fear is a perceptual deficit (Shepard, 1987). In line with this, examples from research in humans show that fearful individuals judge neutral faces as more negative (Richards et al., 2002; Bell et al., 2011), and that individuals with spider phobia more easily see a spider in pictures morphing from flowers to spiders (Kolassa et al., 2007). Only recently it became evident that fear generalization not solely depends on the physical properties of threatening stimuli but also on their conceptual properties (Dunsmoor et al., 2009, 2011, 2012; Soeter and Kindt, 2012, 2015; Kindt, 2014). This raises the question whether fear generalization observed for perceptual cues (such as when a piece of dust triggers a fear response) is in fact a perceptual process, or may instead emerge at a later stage of processing, when activated fear associations start guiding (biasing) the interpretation of a stimulus.

As the observed behavior does not reveal whether overgeneralization of fear already occurs during the initial perception and categorization of a stimulus, or emerges at a later stage, it is necessary to go beyond behavioral observations to study the (neural) processes that drive these behaviors. A number of studies have begun to elucidate brain processes involved in fear-related perceptual biases. These studies mainly found heightened sensory sensitivity to all external stimuli in high fearful individuals, expressed as enhanced early (100 ms) event-related potentials (ERPs; Kolassa et al., 2007, 2009; Frenkel and Bar-Haim, 2011; Weymar et al., 2013) and heightened responses in visual areas to phobogenic objects, often paralleled by heightened responses in the amygdala (Dilger et al., 2003; Straube et al., 2006; Alpers et al., 2009). These findings are in line with the commonly observed fear-related attentional bias
(Bar-Haim et al., 2007), suggesting that fear facilitates afferent cortical processing in the human visual cortex when individuals search for potential threat. However, although heightened sensory sensitivity may explain a faster detection of a stimulus, it does not necessarily imply or explain a biased classification of that stimulus.

Studies on normal fear generalization have found that varying degrees of perceptual resemblance to a conditioned stimulus elicit graded responses (generalization curves) in the same neurocircuitry as is involved in the acquisition and expression of conditioned fear (i.e., insula, dorsal anterior cingulate cortex; Dymond et al., 2014), and in salience processing in general (e.g., the ventral tegmental area; Cha et al., 2014). While normally these graded responses inversely relate to activation in inhibitory brain systems, such as the hippocampus and the ventromedial prefrontal cortex, individuals with generalized anxiety seem specifically impaired in recruiting these systems, broadening the range of stimuli to which they respond with fear (Greenberg et al., 2013; Cha et al., 2014; Bishop et al., 2015).

Even though the aforementioned studies provided useful insights into the brain areas that are hyper- or hypoactive in anxiety disorders, they do not distinguish between a perceptual and a conceptual account of overgeneralization of fear in anxiety disorders. An increased neural response to a stimulus does not specify how that stimulus is categorized (e.g., high anxious individuals may exhibit heightened sensory sensitivity to virtually all stimuli, while only displaying a classification bias for a subset of stimuli). Univariate techniques therefore seem unsuited for addressing the question as to where in the cortical hierarchy ambiguous stimuli are originally marked as threatening.

In contrast, multi-voxel pattern analysis (MVPA) evaluates the information across groups of voxels, to characterize the unique neural representation of a stimulus within a certain brain region (Haxby et al., 2001). By training a classifier on neural patterns related to distinct stimulus classes one can classify patterns related to novel stimuli, providing a more sensitive way to assess the degree to which different stimuli or cognitive states are alike (Haynes and Rees, 2005; Kamitani and Tong, 2005; Norman et al., 2006; Kriegeskorte et al., 2008), or altered by fear (Li et al., 2008; Visser et al., 2011, 2013, 2015, 2016; Dunsmoor et al., 2014).

Here, we combined functional magnetic resonance imaging (fMRI) with an adapted version of the task used by Kolassa et al. (2007), to study overgeneralization of fear in individuals with low and high fear of spiders. Based on previous work, we predicted that individuals with high spider fear (HSF) would be more likely to classify ambiguous morphs as spiders than individuals with low spider fear (LSF). Furthermore, we examined in a datadriven manner whether overgeneralization of fear is associated with functional anomalies in regions traditionally associated with (1) early perception and object identification (Ungerleider and Haxby, 1994), which would support a perceptual account, and/or 2) regions involved in saliency (Etkin and Wager, 2007; Seeley et al., 2007; Hermans et al., 2011; Ipser et al., 2013), and higher cognitive processes (Miller and Cohen, 2001), which would support a more conceptual account. Of course, if a bias is already present in low-level areas it is likely to be present in higher-level areas as well, given that these areas respond to the information 
relayed from lower-level areas. If, however, a bias does not emerge until later in the processing stream, this could be an indication that the stimulus is initially correctly identified as nonthreatening. Yet higher in the processing-stream certain features of the stimulus may still trigger semantic associations with the feared object, which in turn may evoke unpleasant feelings and biased decision making. Using support vector machine (SVM) classification in functional regions of interest we assessed at what point in the information-processing stream (i.e., 'low-level' visual areas, and/or 'higher' areas associated with the attribution of significance and decision making) this bias would become apparent.

\section{MATERIALS AND METHODS}

\section{Participants}

Participants were recruited by means of advertisements in newspapers, social media and the university website. Selection was based on self-reported spider fear as measured by the Spider Phobic Questionnaire (SPQ; Klorman et al., 1974), with scores above 16 representing HSF and scores below 6 representing LSF. Of the 44 participants that were initially included, one participant was excluded because of excessive sleepiness, three participants because they did not comply with task instructions, and two participants because of excessive head motion. The final sample included 18 participants in the HSF condition (all females, three left-handed, mean $=24.1 \pm 5.9$ SD years of age), and 20 participants in the LSF condition (14 females, two left-handed, mean $=22.9 \pm 1.8$ SD years of age). Participants earned $€ 20,-$ for their participation. All participants gave their written informed consent before participating and had normal or corrected-tonormal vision. None of the participants had knowledge of the Chinese language (see Materials and Methods). Procedures were executed in compliance with relevant laws and institutional guidelines, and were approved by the University of Amsterdam's ethics committee (2014-CP-3390).

\section{Apparatus and Materials Stimuli}

The experiment consisted of one session of fMRI scanning, during which participants performed a task aimed to assess overgeneralization of spider fear (Figure 1A). This task was a modified version of the task used by Kolassa et al. (2007), who generously provided part of the stimulus material. This material consisted of schematic morphs that gradually transformed from a flower into a spider by shifting the outlines of the petals until they turned into spider legs (Figure 1B). Three variations existed of this continuum, with each continuum consisting of seven steps, yielding a total of 21 morphs. The presentation of a morph was alternated with the presentation of an unambiguous picture (Figure 1B), which was either a spider $(n=7)$, a flower $(n=7)$, or a Chinese character $(n=7)$. We collected these unambiguous pictures from the Web, adjusted their luminance, and separated them from their original background. Both the morphs and unambiguous pictures were presented on a gray background.

\section{Subjective Measures}

Fear of spiders was assessed with the SPQ (Klorman et al., 1974) and used to select participants. Prior to the experiment, trait anxiety and anxiety sensitivity were assessed with the Trait Anxiety inventory (STAI-T; Spielberger, 1983) and the Anxiety Sensitivity Index (ASI; Peterson and Reiss, 1993), respectively. State anxiety was assessed before and after the scanning procedure with the State Anxiety inventory (STAI-S; Spielberger, 1983).

\section{Image Acquisition}

Scanning was performed on a 3T Philips Achieva TX magnetic resonance imaging (MRI) scanner using a 32-channel head-coil. Functional data were acquired using a gradient-echo, echo-planar pulse sequence $\left(\mathrm{TR}=2000 \mathrm{~ms} ; \mathrm{TE}=27.63 \mathrm{~ms} ; \mathrm{FA}=76.1^{\circ} ; 37\right.$ axial slices with ascending acquisition; $3 \mathrm{~mm} \times 3 \mathrm{~mm} \times 3.3 \mathrm{~mm}$ voxel size; $80 \times 80$ matrix; $240 \times 133.98 \times 240 \mathrm{FoV})$ and consisted of 415 dynamics. Foam pads minimized head motion, and online motion correction was applied by comparing each recorded volume to the initially recorded volume and adjusting the plane of recording with the displacement. A high-resolution $3 \mathrm{D}$ T1-weighted image $\left(\mathrm{TR}=8.30 \mathrm{~ms}, \mathrm{TE}=3.82 \mathrm{~ms}, \mathrm{FA}=8^{\circ}\right.$; $1 \mathrm{~mm} \times 1 \mathrm{~mm} \times 1 \mathrm{~mm}$ voxel size; $240 \times 220 \times 188 \mathrm{FoV})$ was additionally collected for anatomical visualization. Stimuli were backward-projected onto a screen that was viewed through a mirror attached to the head-coil.

\section{Pre-processing}

Functional magnetic resonance imaging data processing was carried out using FEAT (FMRI Expert Analysis Tool) Version 6.00, part of FSL (FMRIB's Software Library ${ }^{1}$ ). Pre-processing included motion correction using MCFLIRT (Jenkinson et al., 2002); slice-timing correction; non-brain removal using BET (Smith, 2002); high-pass temporal filtering ( $\sigma=50 \mathrm{~s}$ ), $5 \mathrm{~mm}$ spatial filtering and pre-whitening (Woolrich et al., 2001). Functional images were coregistered to each individual's high resolution structural images using FLIRT (Jenkinson and Smith, 2001; Jenkinson et al., 2002). Registration from high resolution structural to standard space (MNI152 template, $2 \mathrm{~mm}$ ) was then carried out using FNIRT non-linear registration (Andersson et al., 2007).

\section{Experimental Design}

Upon arrival participants were screened and instructed about the scanning procedure. The experiment started with a structural scan. During functional scanning participants performed the generalization task, viewing morphs (ambiguous) as well as pictures (unambiguous; Figures 1A,B). Participants were requested to make a response after each stimulus by pressing a button, indicating whether they had seen a spider, a flower, or none of the two (represented by a question mark). With regard to the morphs, we informed participants that the 'drawings' they would be seeing would resemble spiders or flowers to a certain degree, while a proportion of these drawings would resemble none of the two. We emphasized that responses to

\footnotetext{
${ }^{1}$ www.fmrib.ox.ac.uk/fsl
} 


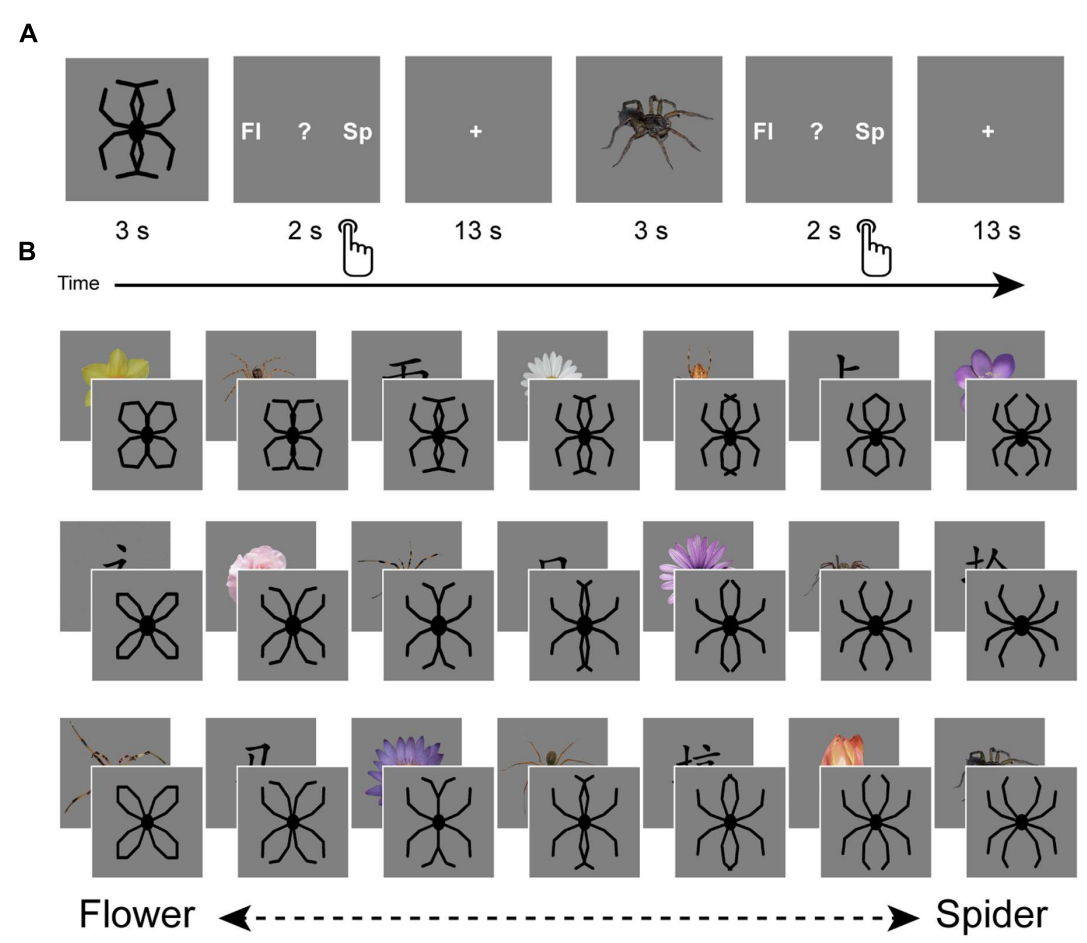

FIGURE 1 | Design. The experiment consisted of one session of fMRI scanning during which a generalization task was performed (A). This task consisted of the presentation of schematic flowers morphing to spiders (generously provided by Kolassa et al., 2007), intermitted by pictures of spiders, flowers and Chinese characters. Participants had to indicate whether they saw a spider ('sp'), a flower ('fl') or none of the two ('?'). Response buttons were counterbalanced over participants. Three variations existed of this flower-spider continuum (B). Each variation was presented once, but the fixed order of stimulus presentation (counterbalanced over participants) was designed in such a way that priming effects could be averaged out: each step of the continuum was once preceded by a flower, once by a spider and once by a Chinese character. Images are not to scale.

these drawings were purely subjective and that there were no right or wrong answers. Furthermore, we explicitly instructed participants to wait until the stimulus (3 s) disappeared and the response screen ( $2 \mathrm{~s}$ ) was presented. Consequently, reaction times cannot be reliably interpreted, as they do not reflect the initial response to the picture. The response screen (Figure 1A) reminded participants which button to press (left, middle, or right), but only the first two letters of the options were shown ('fl,' '?', 'sp'). The Chinese characters were included to introduce a clear 'none-of-the-two' category, so that responses to the morphs were not biased by response frequencies to the unambiguous stimuli. Stimulus presentation was fixed and was designed in such a way that priming effects could be averaged out: each step of the continuum was once preceded by a flower, once by a spider and once by a Chinese character (Figure 1B). Response buttons and stimulus presentation were counterbalanced across participants. Inter-trial intervals were fixed and relatively long (13 s), which seems optimal for single-trial pattern analysis (Visser et al., 2016). The task started with three practice trials (unambiguous pictures of a flower and a spider, and a Chinese character), which were discarded from further analysis. Participants were instructed to pay close attention to the pictures, even if pictures were unpleasant. Continuous eyetracker-recordings ensured that participants complied with these instructions.

\section{Univariate fMRI Analysis}

In order to create functional regions of interest (ROIs), and to facilitate interpretation of the results in light of previous fMRI studies on spider fear, we ran a standard voxelwise wholebrain analysis, modeling all trials within a condition as one regressor [10 regressors in total: seven morph steps (three per step), unambiguous flowers (7), unambiguous spiders (7) and Chinese characters (7)] and including six motion parameters and temporal derivatives as regressors of no interest. Higherlevel mixed-effects analyses were conducted to assess group differences in the contrast of interest, that is, unambiguous spiders $>$ unambiguous flowers. Furthermore, we explored whether there were voxels which' tuning curve followed the gradient of flowers morphing to spiders (i.e., we set up a contrast to test whether there was a linear increase or decrease as function of morphing) and whether these voxels showed overlap with the ones identified using the multivariate approach. Activation was thresholded at $Z>2.3$ ( $Z>3.1$ for creating the ROIs) and clustercorrected at $p<0.05$. Finally, we plotted for each of the functional ROIs the average activation per stimulus type, to examine if the generalization curves mirrored the behavioral data.

\section{Region of Interest Selection}

The parametric map obtained for the contrast unambiguous spiders $>$ unambiguous flowers was thresholded at $Z>3.1$ and 
masked with a whole brain mask created from the HarvardOxford cortical and subcortical atlas (part of the FSL software), which excluded brain stem and cerebellum and was thresholded at a probability of $>10 \%$. Next, 12 ROIs were created from clusters consisting of at least 100 adjacent voxels. Using these functional ROIs, we then classified the ambiguous stimuli using a SVM (see first two paragraphs of Section "Multi-voxel Pattern Analysis"). This selection of ROIs represented a sample of different areas in the information-processing stream, with a high likelihood of being responsive to the task (as areas that distinguish between unambiguous stimuli may also be responsive to gradual changes in their features).

\section{Multi-Voxel Pattern Analysis}

Each trial was modeled as a separate regressor in a general linear model (GLM), including six motion parameters as regressors of no interest. The resulting parameter estimates were normalized to down-weight noisy voxels, by dividing each voxel's parameter estimate by the standard error of that voxel's residual error term after fitting the first-level GLM. In Matlab (version 8.0; MathWorks) we created for each participant, for each ROI a vector containing the normalized parameter estimates per voxel for a particular trial. Next, these vectors were used for classification analysis (next paragraph).

For each participant, we performed a leave-two-out classification analysis with 1,000 iterations within each functional ROI, using a two-class SVM with a linear Kernel function (LIBSVM, Chang and Lin, 2011), Software available at http://www.csie.ntu.edu.tw/ cjlin/libsvm. With each iteration two unambiguous stimuli (one flower and one spider) were separated as test set, while the other unambiguous stimuli (six flowers and six spiders) were used to train the classifier (random selection with replacement). Next, the two separated stimuli as well as the 21 ambiguous stimuli were classified, yielding a total number of 23 classifications per iteration (one flower, one spider, and 21 morphs). These classifications were averaged over iterations and over the different stimulus types (spider, flower and seven steps of the flower-spider continuum).

\section{Statistical Analyses Behavioral Data}

The behavioral responses, denoted by $Y$, were dichotomized ( $Y=1$ for "spider," $Y=0$ for other responses). To account for the nesting of stimulus responses within persons, the data were modeled with a mixed logistic regression model: $P(Y=1)=\exp (Z) /(1+\exp (Z))$, where $P(Y=1)$ denotes the probability that $Y=1$, and where $Z$ denotes a linear combination of fixed and random effects. Note that these models could also be considered as mixed Rasch models (Rijmen et al., 2003; Kolassa et al., 2007). We considered four models: model 1 consisted of a fixed group effect (LSF vs. HSF, coded as 0 and 1, respectively) and a random person effect. Model 2 consisted of a fixed stimulus effect (the degree to which a stimulus resembles a spider, seven levels) and a random person effect. Model 3 consisted of a fixed stimulus effect, a fixed group effect, and a random person effect. Model 4 consisted of a fixed stimulus effect, a fixed group effect, a multivariate random person effect with a variance parameter for each group, and a covariance parameter between the two groups.

The model fit was evaluated with AIC and BIC fit statistics, as well as with likelihood ratio tests for nested models. The models were estimated with the statistical software package $R$, version 3.1.1. (R Core Team, 2014) using the glmer() function within the R-package 'lme4' (De Boeck et al., 2011; Bates et al., 2013).

\section{SVM Classification}

By iterating training and test sets we obtained normally distributed classification scores for the brain data. Hence, we used parametric tests to assess whether the classification of blood oxygenation level dependent (BOLD-MRI) patterns, obtained on the individual level, revealed on average more spider classifications in the HSF group, compared to the LSF group. Statistical tests were performed using SPSS (version 21). We first assessed per ROI, per group, whether the classification of the unambiguous spider and flower stimuli was above chance level (0.5), using a one-sample $t$-test, to get a sense of the reliability of the SVM classification in that area. Next, we performed a mixed between-within-subjects analysis of variance (ANOVA) within each ROI, with morph as within-subject factor and group as between-subject factor. We specifically tested whether there was a main effect of stimulus type (indicating that the region was sensitive to changes in stimulus features), and if significant or trend-significant, whether there was a main effect of group. Predictions were tested while correcting for multiple comparisons (the number of ROIs) by limiting the false discovery rate (Benjamini and Hochberg, 1995). In case that the assumption of sphericity was violated a Greenhouse-Geisser correction was applied. All $p$-values are reported two-sided, with the significance level set at $\alpha=0.05$.

\section{RESULTS}

\section{Participant Characteristics}

Participants in the LSF and HSF group did not differ in trait anxiety and anxiety sensitivity $\left(F_{1,36}=0.04 ; p=0.847\right.$; $F_{1,36}=1.22 ; p=0.277$, respectively; Table 1). In the HSF group, the (anticipated) confrontation with spider-related material was

TABLE 1 | Mean values \pm SD of self-reported fear of spiders (SPQ), anxiety sensitivity (ASI), state anxiety (STAI-S, pre- and post-scan), and trait anxiety (STAI-T) per group.

\begin{tabular}{lcc}
\hline & HSF $(\boldsymbol{n}=\mathbf{1 8})$ & LSF $(\boldsymbol{n}=\mathbf{2 0})$ \\
\hline SPQ & $21.0( \pm 3.0)^{*}$ & $3.2( \pm 1.6)^{*}$ \\
ASI & $8.3( \pm 4.2)$ & $10.0( \pm 5.0)$ \\
STAl-T & $35.2( \pm 9.5)$ & $35.8( \pm 9.0)$ \\
STAl-S pre & $36.4( \pm 9.1)^{*}$ & $29.3( \pm 8.5)^{* a}$ \\
STAI-S post & $35.7( \pm 13.8)^{\#}$ & $28.5( \pm 7.4)^{\# a}$ \\
\hline
\end{tabular}

aBased on 19 participants. SPQ, spider phobia questionnaire; ASI, Anxiety Sensitivity Index; HSF, high spider fear; LSF, low spider fear. Significant and trend-significant group effects are marked as follows: * $p<0.050 ;{ }^{*} p<0.080$. 


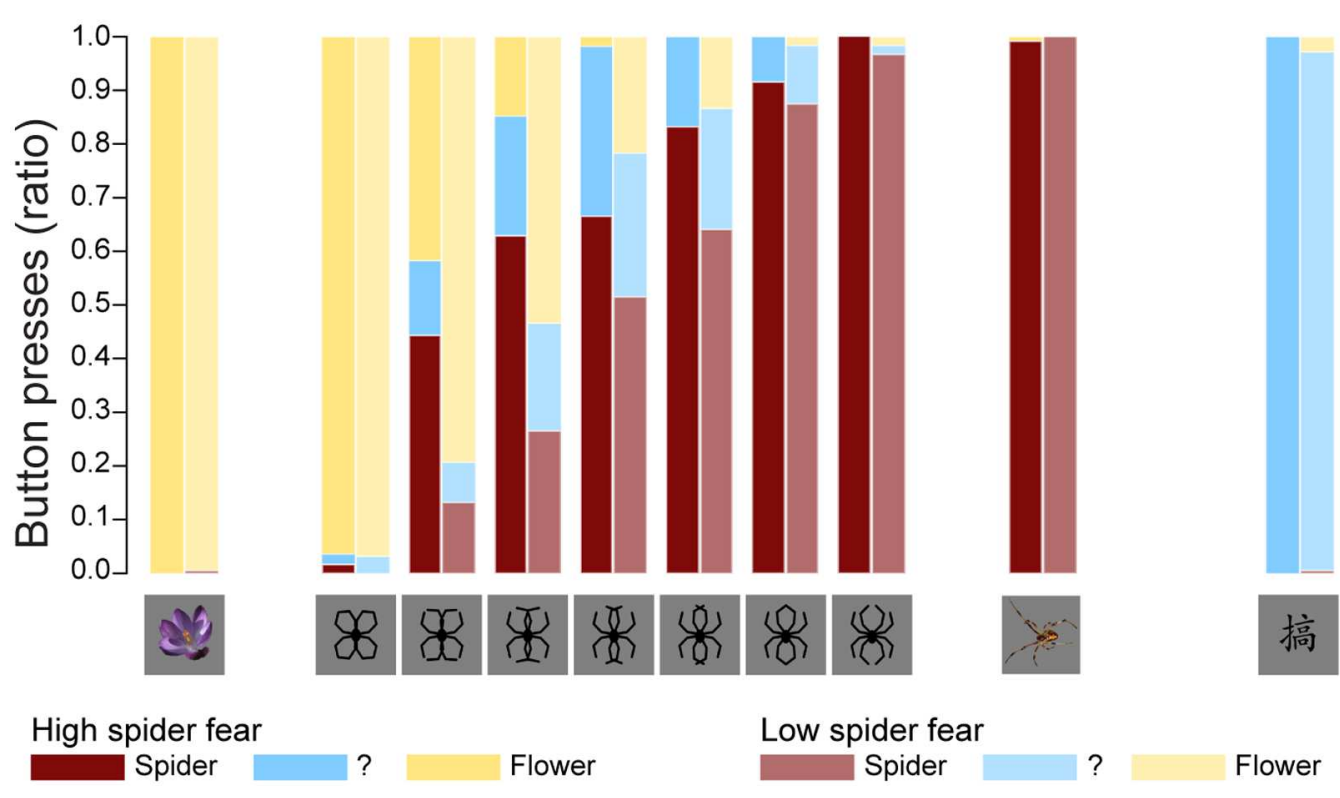

FIGURE 2 | Behavioral data. The average proportions in both groups of stimuli identified as spiders, flowers, or neither/nor. These results replicate previous findings (Kolassa et al., 2007), suggesting that an individual with high fear of spiders is more likely to classify an ambiguous stimulus as a spider.

TABLE 2 | Number of estimated parameters (df), log-likelihood (logLik), AIC, BIC, and Akaike weights of the four models described in section on Univariate fMRI Analysis.

\begin{tabular}{|c|c|c|c|c|c|}
\hline & df & logLik & AIC & BIC & Akaike weights \\
\hline Model 1 & 3 & -529.72 & 1065.44 & 1079.48 & 0.000 \\
\hline Model 2 & 8 & -303.43 & 622.86 & 660.32 & 0.042 \\
\hline Model 3 & 9 & -299.53 & 617.05 & 659.19 & 0.771 \\
\hline Model 4 & 11 & -298.95 & 619.89 & 671.40 & 0.186 \\
\hline
\end{tabular}

associated with higher state anxiety before scanning $\left(F_{1,35}=6.02\right.$, $\left.p=0.019, \eta_{\mathrm{p}}^{2}=0.15\right)$, and marginally higher state anxiety after scanning $\left(F_{1,35}=3.97, p=0.054, \eta_{\mathrm{p}}^{2}=0.10\right)$.

\section{Behavioral Responses}

Figure 2 displays the average proportions in both groups of stimuli identified as spiders, flowers, or neither/nor. Table 2 summarizes the fit of the four models as described in the Section "Statistical Analyses."

The fit statistics indicate that model 3 (i.e., the model with a fixed stimulus effect, a fixed group effect, and a random person effect) was the best fitting model. This conclusion was supported by the results of the likelihood ratio tests in Table 3 . The fit of model 3 was significantly better than the fit of models 1 and 2 ,

TABLE 3 | Results likelihood ratio tests.

\begin{tabular}{lccc}
\hline & -2log(Lik-ratio) & df & $\boldsymbol{p}$ \\
\hline Model 1 vs. model 3 & 460.38 & 6 & $<0.0001$ \\
Model 2 vs. model 3 & 7.80 & 1 & 0.005 \\
Model 3 vs. model 4 & 1.16 & 2 & 0.56
\end{tabular}

while the fit of model 4 was not significantly better than the fit of model 3.

The parameter estimates of model 3 are displayed in Table 4. The interpretation of the parameters is as follows: since LSF is arbitrarily chosen as reference group, the probability that

TABLE 4 | Parameter estimates of model 3.

\begin{tabular}{lrc}
\hline Parameter $^{\text {a }}$ & Estimate & SE \\
\hline Fixed effects: & -6.4112 & 1.1208 \\
Morph 1 & -2.0682 & 0.4191 \\
Morph 2 & -0.9872 & 0.3895 \\
Morph 3 & -0.2625 & 0.3827 \\
Morph 4 & 0.6497 & 0.3896 \\
Morph 5 & 1.9926 & 0.4402 \\
Morph 6 & 3.7894 & 0.6796 \\
Morph 7 & 1.4036 & 0.4859 \\
Group & & \\
Random effect: & 1.314 & \\
Intercept person (SD) & & \\
\hline aEstimates based on the following parameterization: glmer [Y - & + stimulus + \\
group + (1 | person), family = binomial]. &
\end{tabular}


a randomly selected person with LSF will classify morph 3 as "spider" is $\exp (-0.9872) /(1+\exp (-0.9872))=0.271$, while the probability that a randomly selected person with HSF will classify morph 3 as "spider" is $\exp (-0.9872+1.4036) /(1+\exp (-0.9872+1.4036))=0.603$. Note that the estimates of the stimulus parameters increase from morph 1 to 7 , which implies that the probability that a stimulus will be classified as spider increases from morph 1 to 7 . The estimated group effect is statistically significant, $z=2.889$, $p=0.004$. These results replicate previous findings (Kolassa et al., 2007), suggesting that an individual with high fear of spiders is more likely to classify an ambiguous stimulus as a spider.

\section{Univariate fMRI Results}

Whole brain univariate analyses showed typical salience-network activation in response to spider pictures compared to flower pictures (Table 5 and Figure 3). This effect was strongest in individuals with HSF, who showed more activation in the salience network as well as visual (association) areas, than individuals with LSF (Table 5). These results are in line with previous findings (Dilger et al., 2003; Straube et al., 2006; Alpers et al., 2009). Univariate analysis on activity related to the ambiguous stimuli revealed a cluster in the occipital cortex that responded more to 'spiderness' and a cluster in the dorsal paracingulate cortex that responded more to 'flowerness', but no group differences were observed here (Table 6). Finally, Figure 4 shows the average activation per stimulus type, in 12 functional ROIs. Although individuals with high fear of spiders showed on average more activation than individuals with low fear of spiders in the occipital cortex and a cluster comprising the left amygdala and insula, these effects only reached trend significance $\left(F_{1,36}=3.13\right.$; $p=0.085$ and $F_{1,36}=3.20 ; p=0.082$, respectively) and were not specific for ambiguous stimuli (i.e., no effects of morph step in any of the ROIs).

\section{Classification Results}

Table 7 displays the proportions of correctly classified neural response patterns related to the unambiguous stimuli, in 12 functional ROIs. In most occipital areas, classification accuracy was significantly above chance for both the HSF and the LSF group. Additionally, in the HSF group classification was above chance in amygdala, insula, anterior cingulate cortex, supramarginal gyrus, and the precentral gyrus. An exploratory analysis showed that in these areas (ROI 3-5, 11-12) the classification of unambiguous spiders was significantly higher in the HSF group than in the LSF group (all ps < 0.018), suggesting that the pictures of real spiders elicited more generalized responses when individuals were afraid of spiders (Watts and Dalgleish, 1991).

With regard to the morphs (ambiguous stimuli), no group differences were observed in the proportion of response patterns

TABLE 5 | Brain areas showing differential activation for the unambiguous pictures $(n=38)$.

\begin{tabular}{|c|c|c|c|c|c|}
\hline \multirow[t]{2}{*}{ Brain region (COG) } & \multicolumn{3}{|c|}{ MNI coordinates } & \multicolumn{2}{|c|}{ Volume } \\
\hline & $x$ & $y$ & $z$ & \# voxels & Maximum Z \\
\hline \multicolumn{6}{|l|}{ Spider > Flower } \\
\hline \multicolumn{6}{|l|}{ Group mean $(n=38)$} \\
\hline $\begin{array}{l}\text { Salience network (i.e., frontoinsular cortex, orbitofrontal cortex, dorsal anterior } \\
\text { cingulate extending into posterior cingulate cortex, paracingulate cortex, superior } \\
\text { frontal gyrus and juxtapositional lobule cortex, temporoparietal junction, amygdala, } \\
\text { thalamus, brainstem, cerebellum) and lateral occipital cortex }\end{array}$ & 1 & 1 & -27 & 69638 & 8.49 \\
\hline \multicolumn{6}{|l|}{ High spider fear $(n=18)>$ Low spider fear $(n=20)$} \\
\hline Lingual gyrus, precuneus, intracalcarine cortex & -3 & -62 & 10 & 14658 & 4.91 \\
\hline R superior, middle frontal gyrus, precentral gyrus & 23 & 4 & 54 & 1354 & 4.16 \\
\hline R insula, frontal operculum, orbitofrontal cortex & 49 & 16 & -5 & 1308 & 4.65 \\
\hline $\begin{array}{l}\text { R middle temporal gyrus (temporooccipital part), lateral occipital cortex (inferior } \\
\text { division), angular gyrus, parietal operculum cortex, supramarginal gyrus }\end{array}$ & 56 & -52 & 12 & 1137 & 4.13 \\
\hline Anterior cingulate cortex & 1 & 18 & 25 & 1102 & 3.95 \\
\hline L insula, frontal operculum, orbitofrontal cortex & -39 & 12 & -8 & 704 & 3.89 \\
\hline L parietal operculum cortex, supramarginal gyrus & -56 & -39 & 28 & 520 & 3.8 \\
\hline \multicolumn{6}{|l|}{ Flower > Spider } \\
\hline \multicolumn{6}{|l|}{ Group mean $(n=38)$} \\
\hline R precentral gyrus, $R$ post-central gyrus & 9 & -31 & 67 & 473 & 3.60 \\
\hline \multicolumn{6}{|l|}{ High spider fear $(n=18)>$ Low spider fear $(n=20)$} \\
\hline No significant clusters & & & & & \\
\hline
\end{tabular}




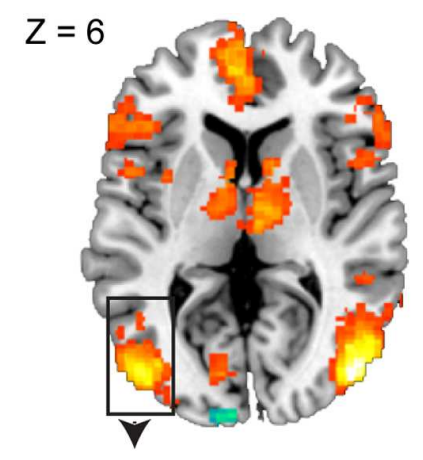

Lateral occipital cortex, inferior division

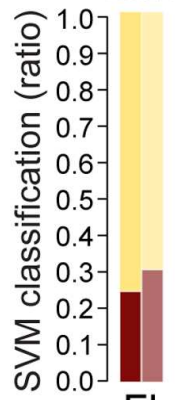

$\mathrm{FI}$



High spider fear
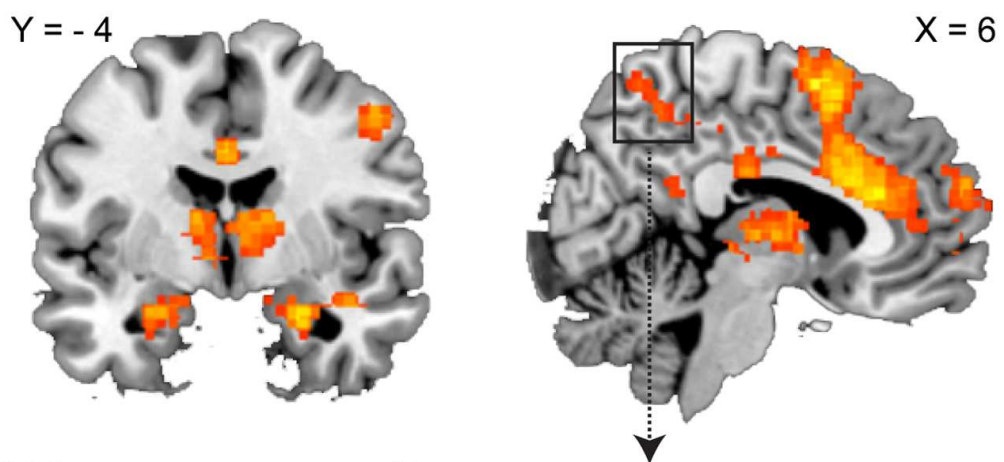

Precuneus
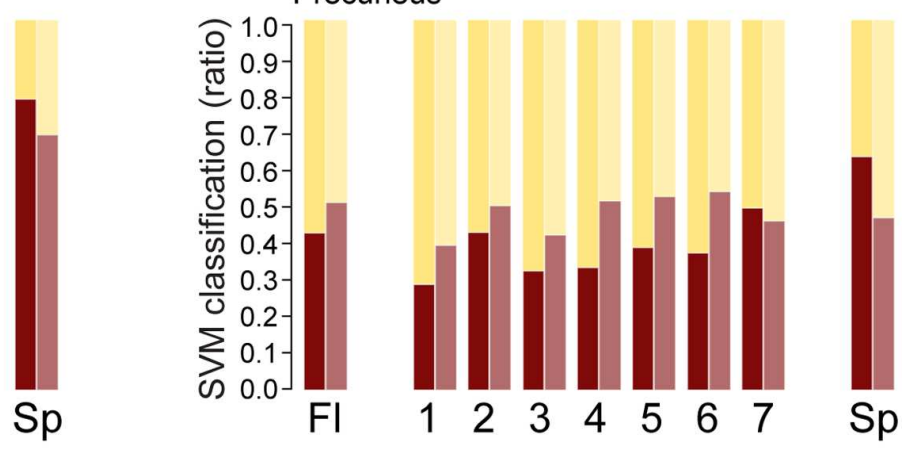

Low spider fear



FIGURE 3 | Neural classification. Univariate parametric maps showing clusters of voxels that discriminate between unambiguous flower and spider pictures (top panels, $Z>3.1$, cluster corrected at $p<0.05$ ). Bottom panels show the average SVM classifications in two functional ROIs. In the lateral occipital cortex response patterns were more often classified as spider in individuals with low spider fear ( $p<0.029$; uncorrected).

TABLE 6 | Brain areas showing differential activation for the ambiguous pictures $(n=38)$.

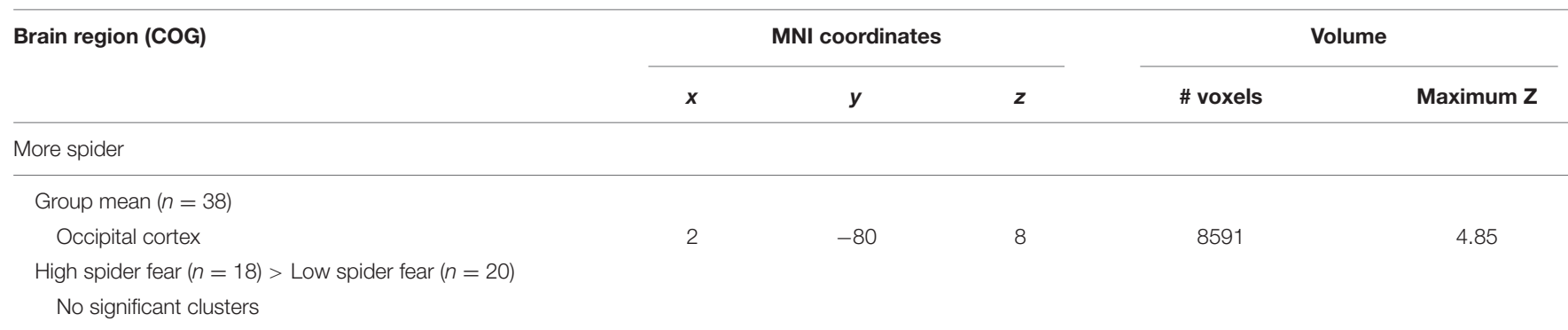

\section{More flower}

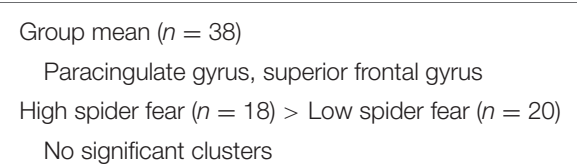

No significant clusters

4

35

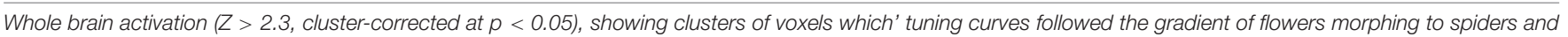

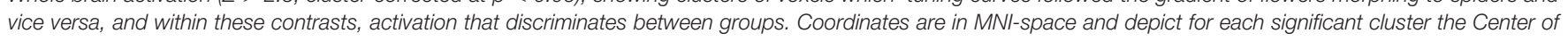
Gravity (COG). Labels are derived from the Harvard-Oxford cortical and subcortical atlases.

classified as spider (Table 8), except for a small (uncorrected) effect in the left lateral occipital cortex. This effects was even in the opposite direction as hypothesized, given that response patterns were more likely to be classified as spiders when individuals were not afraid of spiders (Figure 3, left panel).
It is noteworthy that the classification did not change substantially when we corrected for average activation, which we did by subtracting the signal per trial, averaged across voxels within that ROI (i.e., preserving the spatial pattern, but scaling the activation so that every trial's mean activation in a particular ROI was zero). 

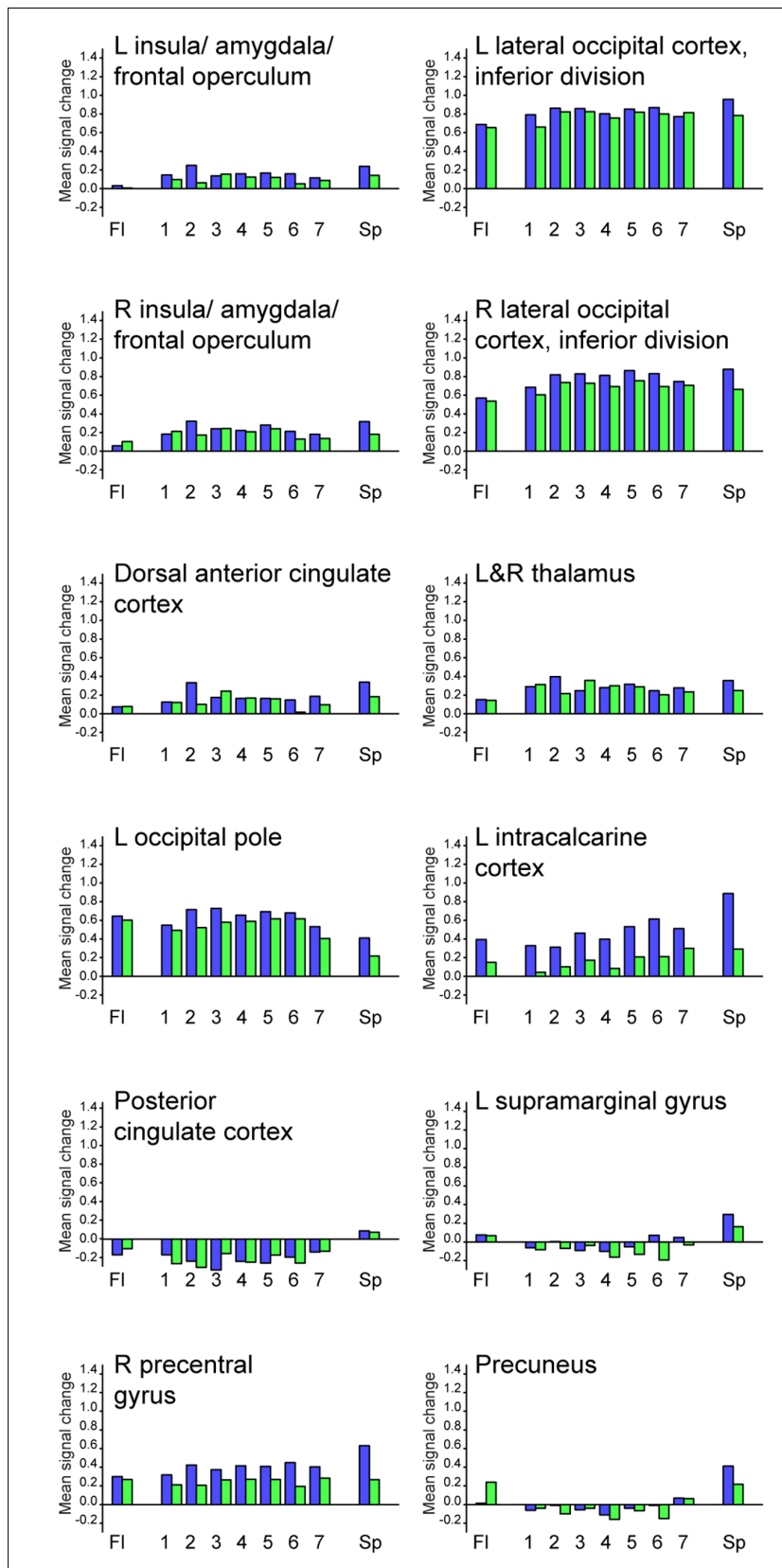

High spider fear

Low spider fear

FIGURE 4 | Average activation per stimulus type, in 12 functional ROIs. $L=$ left; $R=$ right.

\section{DISCUSSION}

The aim of the present study was to examine how fear influences the processing of ambiguous stimuli. We used SVM classification to explore whether overgeneralization of fear is associated with functional anomalies in regions traditionally associated with early perception and object identification, and/or with regions involved in saliency and higher cognitive processes. Identifying where in the information-processing stream fear affects ambiguity resolution could potentially indicate whether this bias is primarily perceptual, or conceptual in nature.

In line with previous findings (Kolassa et al., 2007), individuals with HSF were more likely to classify ambiguous morphs as spiders than individuals with LSF. Unexpectedly, neither average activation, nor SVM classification in 12 functional ROIs revealed a pattern that mirrored the behavioral effect. We even obtained some evidence that response patterns in visual association areas related to ambiguous stimuli were more likely to be classified as spiders when individuals were not afraid of spiders.

These findings seem to point to a methodological limitation of the current paradigm. Unlike most studies, which used either pictures of phobogenic material (Dilger et al., 2003) or schematic morphs (Kolassa et al., 2007), we alternately presented morphs and pictures of real spiders. In the SVM classification, we trained a classifier on the unambiguous pictures to classify the schematic morphs. This seemed the most ecologically valid approach, as we were interested in the degree to which the morphs would resemble 'true' spiders or flowers, not in the similarity between schematic morphs per se. However, by mixing the two types of stimuli, we may have unintentionally deflated the valence of the spider drawings, skewing the classification of these stimuli. Although these morphs could have been a valid representation of the fearful category if presented alone, the (anticipated) presence of stimuli that are substantially more arousing may have turned the morphs into relatively safe stimuli. For individuals without spider fear both classes of unambiguous stimuli were virtually neutral, so training a classifier on these stimuli showed a linear increase in the likelihood that an ambiguous morph is classified as a spider. In contrast, for individuals with HSF the classifier is trained on two very distinct categories: one neutral and one highly emotional. This is also evident from the fact that these unambiguous categories are better classified - thus more distinct - in high fearful individuals than in low fearful individuals. In this scenario, a relatively neutral morph is classified as a flower, probably not on the basis of perceptual or even conceptual similarity, but on the absence of a strong emotional response. Between-run classification, with ambiguous and unambiguous stimuli presented in separate runs, could partially solve this problem: without the continuous anticipation of the (terrifying) unambiguous spider pictures, the spider drawings could be semantically categorized as spiders, instead of merely being categorized as 'relatively safe.' Between-run classification also has the advantage of ensuring complete independence between train and test set, thereby preventing possible biases in pattern classification (Mumford et al., 2014). Yet, even in separate runs, the unambiguous spider pictures will undoubtedly elicit a much stronger emotional response than the morphs, which may still hamper a balanced classification of stimulus categories if the unambiguous stimuli were to be used for training. This exemplifies that it is methodologically challenging to classify emotional and neutral stimuli in groups that differ in their judgment of emotionality. 
TABLE 7 | Mean values \pm SD from the support vector machine classification of neural patterns related to presentations of unambiguous stimuli, in 12 functional ROls.

\begin{tabular}{|c|c|c|c|c|c|}
\hline \multirow[t]{2}{*}{ Brain region } & \multirow[t]{2}{*}{ \# voxels } & \multicolumn{2}{|c|}{$\begin{array}{l}\text { Proportion of correctly } \\
\text { classified flower stimuli }\end{array}$} & \multicolumn{2}{|c|}{$\begin{array}{l}\text { Proportion of correctly } \\
\text { classified spider stimuli }\end{array}$} \\
\hline & & HSF $(n=18)$ & LSF $(n=20)$ & HSF $(n=18)$ & LSF $(n=20)$ \\
\hline $\begin{array}{l}\text { ROI 1: L amygdala, anterior insula, inferior temporal gyrus, anterior } \\
\text { division, inferior frontal gyrus, frontal operculum, frontal pole }\end{array}$ & 3110 & $0.62 *( \pm 0.22)$ & $0.58^{\#}( \pm 0.20)$ & $0.70^{*}( \pm 0.19)$ & $0.62 *( \pm 0.19)$ \\
\hline $\begin{array}{l}\text { ROI 2: L lateral occipital fusiform cortex, lateral occipital cortex } \\
\text { inferior division, occipital fusiform gyrus }\end{array}$ & 4542 & $0.76^{*}( \pm 0.17)$ & $0.69 *( \pm 0.20)$ & $0.79 *( \pm 0.23)$ & $0.69 *( \pm 0.18)$ \\
\hline $\begin{array}{l}\text { ROI 3: R amygdala, anterior insula, inferior temporal gyrus, anterior } \\
\text { division, inferior frontal gyrus, frontal operculum, frontal pole }\end{array}$ & 3090 & $0.68^{*}( \pm 0.18)$ & $0.57( \pm 0.18)$ & $0.75^{*}( \pm 0.17)$ & $0.61 *( \pm 0.16)$ \\
\hline $\begin{array}{l}\text { ROI 4: R lateral occipital fusiform cortex, lateral occipital cortex } \\
\text { inferior division, occipital fusiform gyrus }\end{array}$ & 4806 & $0.76 *( \pm 0.14)$ & $0.71^{*}( \pm 0.14)$ & $0.84^{*}( \pm 0.16)$ & $0.69 *( \pm 0.11)$ \\
\hline $\begin{array}{l}\text { ROI 5: dorsal anterior cingulate cortex, paracingulate cortex, } \\
\text { superior frontal gyrus, juxtapositional lobule cortex }\end{array}$ & 5044 & $0.62 *( \pm 0.18)$ & $0.49( \pm 0.17)$ & $0.71 *( \pm 0.15)$ & $0.57( \pm 0.18)$ \\
\hline ROI 6: $L$ and $R$ thalamus & 1125 & $0.57^{\#}( \pm 0.16)$ & $0.53( \pm 0.14)$ & $0.59 *( \pm 0.17)$ & $0.57^{*}( \pm 0.15)$ \\
\hline ROI 7: L occipital pole & 113 & $0.61 *( \pm 0.21)$ & $0.64^{*}( \pm 0.16)$ & $0.68^{*}( \pm 0.14)$ & $0.63^{*}( \pm 0.19)$ \\
\hline ROI 8: L intracalcarine cortex & 133 & $0.69 *( \pm 0.17)$ & $0.56( \pm 0.18)$ & $0.68^{*}( \pm 0.18)$ & $0.61 *( \pm 0.19)$ \\
\hline ROI 9: posterior cingulate cortex & 122 & $0.56( \pm 0.16)$ & $0.58^{*}( \pm 0.15)$ & $0.57^{\#}( \pm 0.14)$ & $0.56( \pm 0.16)$ \\
\hline ROI 10: L supramarginal gyrus & 397 & $0.60^{\#}( \pm 0.23)$ & $0.55( \pm 0.14)$ & $0.61^{*}( \pm 0.21)$ & $0.57^{\#}( \pm 0.17)$ \\
\hline ROI 11: R precentral gyrus & 215 & $0.64 *( \pm 0.15)$ & $0.47( \pm 0.14)$ & $0.71^{*}( \pm 0.17)$ & $0.48( \pm 0.15)$ \\
\hline ROI 12: precuneus & 301 & $0.57( \pm 0.23)$ & $0.49( \pm 0.14)$ & $0.63^{*}( \pm 0.18)$ & $0.47( \pm 0.18)$ \\
\hline
\end{tabular}

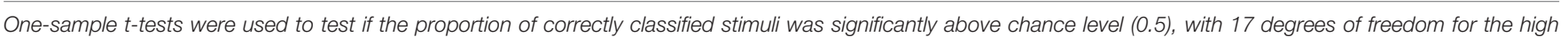
spider fear (HSF) group and 19 degrees of freedom for the low spider fear (LSF) group. ${ }^{*} p<0.050 ;{ }^{\#} p<0.080 . L=$ left; $R=$ right.

TABLE 8 | Summary of statistics of the support vector machine classification of neural patterns related to presentation of morphs ( $n=38)$, in 12 functional ROls.

\begin{tabular}{|c|c|c|c|c|c|c|c|}
\hline \multirow[t]{2}{*}{ Brain region } & \multirow[t]{2}{*}{ \# voxels } & \multicolumn{3}{|c|}{$\begin{array}{l}\text { Main effect of morph (7) } \\
\text { (within-subject) }\end{array}$} & \multicolumn{3}{|c|}{$\begin{array}{l}\text { Main effect of group (2) } \\
\text { (between-subject) }\end{array}$} \\
\hline & & $F_{6,216}$ & $p$ & $\eta_{\mathrm{p}}^{2}$ & $F_{1,36}$ & $p$ & $\eta_{\mathrm{p}}^{2}$ \\
\hline $\begin{array}{l}\text { ROI 1: } L \text { amygdala, anterior insula, inferior temporal gyrus, anterior } \\
\text { division, inferior frontal gyrus, frontal operculum, frontal pole }\end{array}$ & 3110 & 1.86 & 0.089 & 0.049 & 0.296 & 0.590 & 0.01 \\
\hline $\begin{array}{l}\text { ROI 2: L lateral occipital fusiform cortex, lateral occipital cortex } \\
\text { inferior division, occipital fusiform gyrus }\end{array}$ & 4542 & 3.92 & 0.001 & 0.10 & $5.15^{\mathrm{a}}$ & $0.029^{a}$ & $0.13^{a}$ \\
\hline $\begin{array}{l}\text { ROI 3: R amygdala, anterior insula, inferior temporal gyrus, anterior } \\
\text { division, inferior frontal gyrus, frontal operculum, frontal pole }\end{array}$ & 3090 & 2.42 & 0.040 & 0.06 & 1.97 & 0.169 & 0.05 \\
\hline $\begin{array}{l}\text { ROI 4: R lateral occipital fusiform cortex, lateral occipital cortex } \\
\text { inferior division, occipital fusiform gyrus }\end{array}$ & 4806 & 5.26 & $<0.0005$ & 0.13 & 1.57 & 0.218 & 0.04 \\
\hline $\begin{array}{l}\text { ROI 5: Dorsal anterior cingulate cortex, paracingulate cortex, } \\
\text { superior frontal gyrus, juxtapositional lobule cortex }\end{array}$ & 5044 & 2.83 & 0.011 & 0.07 & 1.40 & 0.244 & 0.04 \\
\hline ROI 6: $L$ and $R$ thalamus & 1125 & 0.96 & 0.451 & 0.03 & NT & NT & NT \\
\hline ROI 7: L Occipital pole & 113 & 2.27 & 0.052 & 0.06 & 0.03 & 0.870 & 0.00 \\
\hline ROI 8: L intracalcarine cortex & 133 & 6.11 & $<0.0005$ & 0.15 & 0.12 & 0.734 & 0.00 \\
\hline ROI 9: posterior cingulate cortex & 122 & 0.84 & 0.540 & 0.02 & NT & NT & NT \\
\hline ROI 10: L supramarginal gyrus & 397 & 3.23 & 0.005 & 0.08 & 0.85 & 0.361 & 0.02 \\
\hline ROI 11: R precentral gyrus & 215 & 0.37 & 0.900 & 0.01 & NT & NT & NT \\
\hline ROI 12: precuneus & 301 & 2.26 & 0.039 & 0.06 & $3.88^{\mathrm{a}}$ & $0.056^{\mathrm{a}}$ & $0.10^{\mathrm{a}}$ \\
\hline
\end{tabular}

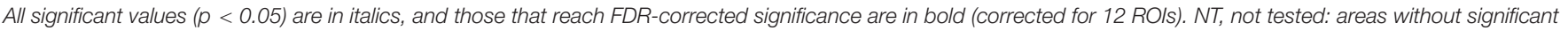

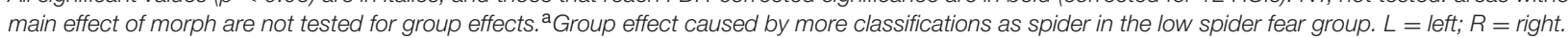


Even though the design may have skewed the classification of morphs in some areas of the brain, participants did eventually indicate that they had seen a spider. Given that every behavioral response must have a neural correlate, one would assume that it should be possible with SVM classification to detect an area that codes for this behavior. We did not find such an area. Again, this suggests that our study design may not have been optimal for detecting subtle effects. While overgeneralization of fear was observed at the level of the group, individual behavior consisted of three discrete responses per stimulus type, yielding a proportion of stimuli classified as flower or spider. Thus, individual behavior was not necessarily representative of the group average. Although we based our behavioral task on previous research (Kolassa et al., 2007), future research should explore the possibility of having participants evaluate ambiguous stimuli on a continuous scale, which seems a more sensitive approach for linking individual behavior to brain data. Further, it may be useful in future research to add a jitter between the presentation of a stimulus and presentation of the response screen, so that responses could be independently modeled as regressor of no interest. This would make it easier to separate decision-making processes from basic perceptual processes. Lastly, the number and spacing of stimuli used in this experiment were based on previous studies. In these studies pattern analysis was applied to distinguish face and house stimuli (Epstein and Kanwisher, 1998; Haxby et al., 2001) and to assess the effects of Pavlovian conditioning (Visser et al., 2011, 2013, 2015, 2016), which is a powerful manipulation. The present manipulation - gradually morphing a flower into a spider - was presumably subtler and therefore required a greater number of trials. Increasing the power and using different behavioral measures would likely yield stronger effects and would open up avenues for model-based searchlights, using (continuous) representational

\section{REFERENCES}

Alpers, G. W., Gerdes, A. B., Lagarie, B., Tabbert, K., Vaitl, D., and Stark, R. (2009). Attention and amygdala activity: an fMRI study with spider pictures in spider phobia. J. Neural. Transm. 116, 747-757. doi: 10.1007/s00702-0080106-8

Andersson, J. L., Jenkinson, M., and Smith, S. (2007). Non-linear Registration, aka Spatial Normalisation FMRIB Technical Report TR07JA2. Oxford: FMRIB Analysis Group of the University of Oxford.

Bar-Haim, Y., Lamy, D., Pergamin, L., Bakermans-Kranenburg, M. J., and Van Ijzendoorn, M. H. (2007). Threat-related attentional bias in anxious and nonanxious individuals: a meta-analytic study. Psychol. Bull. 133:1. doi: 10.1037/0033-2909.133.1.1

Bates, D., Maechler, M., Bolker, B., and Walker, S. (2013). Ime4: Linear MixedEffects Models using Eigen and S4. R Package Version 1.

Bell, C., Bourke, C., Colhoun, H., Carter, F., Frampton, C., and Porter, R. (2011). The misclassification of facial expressions in generalised social phobia. J. Anxiety Disord. 25, 278-283. doi: 10.1016/j.janxdis.2010.10.001

Benjamini, Y., and Hochberg, Y. (1995). Controlling the false discovery rate: a practical and powerful approach to multiple testing. J. R. Stat. Soc. Ser. B 57, 289-300.

Bishop, S. J., Aguirre, G. K., Nunez-Elizalde, A. O., and Toker, D. (2015). Seeing the world through non rose-colored glasses: anxiety and the amygdala response to blended expressions. Front. Hum. Neurosci. 9:152. doi: 10.3389/fnhum.2015.00152 similarity analysis (Kriegeskorte et al., 2008; Kriegeskorte, 2011) instead of the rather coarse (dichotomous) classification analysis. Approaches like these could further elucidate how fear influences the perception, categorization and interpretation of ambiguous stimuli.

In sum, while we found behavioral evidence for overgeneralization of fear in spider phobia, replicating previous findings (Kolassa et al., 2007), we were not able to identify a neural signature of this bias. The question as to where in the information-processing stream this bias emerges therefore remains a topic for further investigation.

\section{AUTHOR CONTRIBUTIONS}

$\mathrm{RV}, \mathrm{PH}$, and MK designed the research; RV and $\mathrm{PH}$ performed the research and analyzed the data; HS and RZ contributed analytic tools; RV and MK wrote the manuscript.

\section{FUNDING}

This study was funded by a Vici grant (Merel Kindt, \#453-07006) from the Netherlands Organization for Scientific Research (NWO) and a grant from the Research Priority Area on Brain and Cognition of the University of Amsterdam.

\section{ACKNOWLEDGMENTS}

The authors would like to thank Marieke Soeter, Judou Breukers, Wouter Cox, Elze Landkroon, Rachel van Loenen, and Norah Schulten for help with recruiting and testing participants, and Lukas Snoek for helpful discussions.

Cha, J., Greenberg, T., Carlson, J. M., DeDora, D. J., Hajcak, G., and MujicaParodi, L. R. (2014). Circuit-wide structural and functional measures predict ventromedial prefrontal cortex fear generalization: implications for generalized anxiety disorder. J. Neurosci. 34, 4043-4053. doi: 10.1523/JNEUROSCI.337213.2014

Chang, C.-C., and Lin, C.-J. (2011). LIBSVM: A library for support vector machines. ACM Trans. Intel. Syst. Technol. 2:27.

De Boeck, P., Bakker, M., Zwitser, R., Nivard, M., Hofman, A., Tuerlinckx, F., et al. (2011). The estimation of item response models with the lmer function from the lme4 package in R. J. Stat. Softw. 39, 1-28. doi: 10.18637/jss. v039.i12

Dilger, S., Straube, T., Mentzel, H.-J., Fitzek, C., Reichenbach, J. R., Hecht, H., et al. (2003). Brain activation to phobia-related pictures in spider phobic humans: an event-related functional magnetic resonance imaging study. Neurosci. Lett. 348, 29-32. doi: 10.1016/S0304-3940(03)00647-5

Dunsmoor, J. E., Kragel, P. A., Martin, A., and LaBar, K. S. (2014). Aversive learning modulates cortical representations of object categories. Cereb. Cortex 24, 2859-2872. doi: 10.1093/cercor/ bht138

Dunsmoor, J. E., Martin, A., and LaBar, K. S. (2012). Role of conceptual knowledge in learning and retention of conditioned fear. Biol. Psychol. 89, 300-305. doi: 10.1016/j.biopsycho.2011.11.002

Dunsmoor, J. E., Mitroff, S. R., and LaBar, K. S. (2009). Generalization of conditioned fear along a dimension of increasing fear intensity. Learn. Mem. 16, 460-469. doi: 10.1101/lm.1431609 
Dunsmoor, J. E., White, A. J., and LaBar, K. S. (2011). Conceptual similarity promotes generalization of higher order fear learning. Learn. Mem. 18, 156160. doi: 10.1101/lm.2016411

Dymond, S., Dunsmoor, J. E., Vervliet, B., Roche, B., and Hermans, D. (2014). Fear generalization in humans: systematic review and implications for anxiety disorder research. Behav. Ther. 46, 561-582.

Epstein, R., and Kanwisher, N. (1998). A cortical representation of the local visual environment. Nature 392, 598-601. doi: 10.1038/33402

Etkin, A., and Wager, T. D. (2007). Functional neuroimaging of anxiety: a meta-analysis of emotional processing in PTSD, social anxiety disorder, and specific phobia. Am. J. Psychiatry 164, 1476-1488. doi: 10.1176/appi.ajp.2007.07 030504

Frenkel, T. I., and Bar-Haim, Y. (2011). Neural activation during the processing of ambiguous fearful facial expressions: an ERP study in anxious and nonanxious individuals. Biol. Psychol. 88, 188-195. doi: 10.1016/j.biopsycho.2011. 08.001

Greenberg, T., Carlson, J. M., Cha, J., Hajcak, G., and Mujica-Parodi, L. R. (2013). Ventromedial prefrontal cortex reactivity is altered in generalized anxiety disorder during fear generalization. Depress. Anxiety 30, 242-250. doi: 10.1002/da.22016

Haxby, J. V., Gobbini, M. I., Furey, M. L., Ishai, A., Schouten, J. L., and Pietrini, P. (2001). Distributed and overlapping representations of faces and objects in ventral temporal cortex. Science 293, 2425-2430. doi: 10.1126/science. 1063736

Haynes, J.-D., and Rees, G. (2005). Predicting the orientation of invisible stimuli from activity in human primary visual cortex. Nat. Neurosci. 8, 686-691. doi: $10.1038 / \mathrm{nn} 1445$

Hermans, E. J., van Marle, H. J., Ossewaarde, L., Henckens, M. J., Qin, S., van Kesteren, M. T., et al. (2011). Stress-related noradrenergic activity prompts large-scale neural network reconfiguration. Science 334, 1151-1153. doi: 10.1126/science. 1209603

Ipser, J. C., Singh, L., and Stein, D. J. (2013). Meta-analysis of functional brain imaging in specific phobia. Psychiatry Clin. Neurosci. 67, 311-322. doi: $10.1111 /$ pcn. 12055

Jenkinson, M., Bannister, P., Brady, M., and Smith, S. (2002). Improved optimization for the robust and accurate linear registration and motion correction of brain images. Neuroimage 17, 825-841. doi: 10.1006/nimg.2002.1132

Jenkinson, M., and Smith, S. (2001). A global optimisation method for robust affine registration of brain images. Med. Image Anal. 5, 143-156. doi: 10.1016/S13618415(01)00036-6

Kamitani, Y., and Tong, F. (2005). Decoding the visual and subjective contents of the human brain. Nat. Neurosci. 8, 679-685. doi: 10.1038/ nn1444

Kindt, M. (2014). A behavioural neuroscience perspective on the aetiology and treatment of anxiety disorders. Behav. Res. Ther. 62, 24-36. doi: 10.1016/j.brat.2014.08.012

Klorman, R., Weerts, T. C., Hastings, J. E., Melamed, B. G., and Lang, P. J. (1974). Psychometric description of some specific-fear questionnaires. Behav. Ther. 5, 401-409. doi: 10.1016/S0005-7894(74)80008-0

Kolassa, I.-T., Buchmann, A., Lauche, R., Kolassa, S., Partchev, I., Miltner, W. H., et al. (2007). Spider phobics more easily see a spider in morphed schematic pictures. Behav. Brain Funct. 3:59. doi: 10.1186/1744-9081-3-59

Kolassa, I.-T., Kolassa, S., Bergmann, S., Lauche, R., Dilger, S., Miltner, W. H., et al. (2009). Interpretive bias in social phobia: an ERP study with morphed emotional schematic faces. Cogn. Emot. 23, 69-95. doi: 10.1080/02699930801940461

Kong, E., Monje, F. J., Hirsch, J., and Pollak, D. D. (2014). Learning not to fear: neural correlates of learned safety. Neuropsychopharmacology 39, 515-527. doi: 10.1038/npp.2013.191

Kriegeskorte, N. (2011). Pattern-information analysis: from stimulus decoding to computational-model testing. Neuroimage 56, 411-421. doi: 10.1016/j.neuroimage.2011.01.061

Kriegeskorte, N., Mur, M., and Bandettini, P. (2008). Representational similarity analysis-connecting the branches of systems neuroscience. Front. Syst. Neurosci. 2:4. doi: 10.3389/neuro.06.004.2008

LeDoux, J. E. (2014). Coming to terms with fear. Proc. Natl. Acad. Sci. U.S.A. 111, 2871-2878. doi: 10.1073/pnas. 1400335111
Li, W., Howard, J. D., Parrish, T. B., and Gottfried, J. A. (2008). Aversive learning enhances perceptual and cortical discrimination of indiscriminable odor cues. Science 319, 1842-1845. doi: 10.1126/science.1152837

Lissek, S., Kaczkurkin, A. N., Rabin, S., Geraci, M., Pine, D. S., and Grillon, C. (2014). Generalized anxiety disorder is associated with overgeneralization of classically conditioned fear. Biol. Psychiatry 75, 909-915. doi: 10.1016/j.biopsych.2013.07.025

Lissek, S., Powers, A. S., McClure, E. B., Phelps, E. A., Woldehawariat, G., Grillon, C., et al. (2005). Classical fear conditioning in the anxiety disorders: a meta-analysis. Behav. Res. Ther. 43, 1391-1424. doi: 10.1016/j.brat.2004.10.007

Mathews, A., and MacLeod, C. (2002). Induced processing biases have causal effects on anxiety. Cogn. Emot. 16, 331-354. doi: 10.1080/02699930143000518

Miller, E. K., and Cohen, J. D. (2001). An integrative theory of prefrontal cortex function. Annu. Rev. Neurosci. 24, 167-202. doi: 10.1146/annurev.neuro.24.1.167

Mineka, S. (1992). Evolutionary memories, emotional processing, and the emotional disorders. Psychol. Learn. Motivat. 28, 161-206. doi: 10.1016/S00797421(08)60490-9

Mineka, S., and Zinbarg, R. (2006). A contemporary learning theory perspective on the etiology of anxiety disorders: it's not what you thought it was. Am. Psychol. 61:10. doi: 10.1037/0003-066X.61.1.10

Mumford, J. A., Davis, T., and Poldrack, R. A. (2014). The impact of study design on pattern estimation for single-trial multivariate pattern analysis. Neuroimage 103, 130-138. doi: 10.1016/j.neuroimage.2014.09.026

Norman, K. A., Polyn, S. M., Detre, G. J., and Haxby, J. V. (2006). Beyond mind-reading: multi-voxel pattern analysis of fMRI data. Trends Cogn. Sci. 10, 424-430. doi: 10.1016/j.tics.2006.07.005

Pavlov, I. P. (1927). Conditioned reflexes: An investigation of the physiological activities of the cerebral cortex. Ann. Neurosci. 17, 136-141.

Peterson, R. A., and Reiss, S. (1993). Anxiety Sensitivity Index Revised Test Manual. Columbus, OH: IDS Publisher.

R Core Team (2014). R: A Language and Environment for Statistical Computing. Available at: https://www.R-project.org.

Richards, A., French, C. C., Calder, A. J., Webb, B., Fox, R., and Young, A. W. (2002). Anxiety-related bias in the classification of emotionally ambiguous facial expressions. Emotion 2:273. doi: 10.1037/1528-3542.2.3.273

Rijmen, F., Tuerlinckx, F., De Boeck, P., and Kuppens, P. (2003). A nonlinear mixed model framework for item response theory. Psychol. Methods 8:185. doi: 10.1037/1082-989X.8.2.185

Seeley, W. W., Menon, V., Schatzberg, A. F., Keller, J., Glover, G. H., Kenna, H., et al. (2007). Dissociable intrinsic connectivity networks for salience processing and executive control. J. Neurosci. 27, 2349-2356. doi: 10.1523/JNEUROSCI.5587-06.2007

Shepard, R. N. (1987). Toward a universal law of generalization for psychological science. Science 237, 1317-1323. doi: 10.1126/science.3629243

Smith, S. M. (2002). Fast robust automated brain extraction. Hum. Brain Mapp. 17, 143-155. doi: 10.1002/hbm.10062

Soeter, M., and Kindt, M. (2012). Stimulation of the noradrenergic system during memory formation impairs extinction learning but not the disruption of reconsolidation. Neuropsychopharmacology 37, 1204-1215. doi: $10.1038 /$ npp. 2011.307

Soeter, M., and Kindt, M. (2015). Retrieval cues that trigger reconsolidation of associative fear memory are not necessarily an exact replica of the original learning experience. Front. Behav. Neurosci. 9:122. doi: 10.3389/fnbeh.2015.00122

Spielberger, C. D. (1983). Manual for the State-Trait Anxiety Inventory. Palo Alto, CA: Consulting Psychologists Press.

Straube, T., Mentzel, H.-J., and Miltner, W. H. (2006). Neural mechanisms of automatic and direct processing of phobogenic stimuli in specific phobia. Biol. Psychiatry 59, 162-170. doi: 10.1016/j.biopsych.2005.06.013

Ungerleider, L. G., and Haxby, J. V. (1994). "What" and "where" in the human brain. Curr. Opin. Neurobiol. 4, 157-165. doi: 10.1016/0959-4388(94)90066-3

Visser, R. M., de Haan Mi, I. C., Beemsterboer, T., Haver, P., Kindt, M., and Scholte, H. S. (2016). Quantifying learning-dependent changes in the brain: single-trial multi-voxel pattern analysis requires slow event-related fMRI. Psychophysiology doi: $10.1111 /$ psyp. 12665

Visser, R. M., Kunze, A. E., Westhoff, B., Scholte, H. S., and Kindt, M. (2015). Representational similarity analysis offers a preview of the 
noradrenergic modulation of long-term fear memory at the time of encoding. Psychoneuroendocrinology 55, 8-20. doi: 10.1016/j.psyneuen.2015. 01.021

Visser, R. M., Scholte, H. S., Beemsterboer, T., and Kindt, M. (2013). Neural pattern similarity predicts long-term fear memory. Nat. Neurosci. 16, 388-390. doi: $10.1038 / \mathrm{nn} .3345$

Visser, R. M., Scholte, H. S., and Kindt, M. (2011). Associative learning increases trial-by-trial similarity of BOLD-MRI patterns. J. Neurosci. 31, 12021-12028. doi: 10.1523/JNEUROSCI.217811.2011

Watts, F. N., and Dalgleish, T. (1991). Memory for phobia-related words in spider phobics. Cogn. Emot. 5, 313-329. doi: 10.1080/02699939108 411043

Weymar, M., Keil, A., and Hamm, A. O. (2013). Timing the fearful brain: unspecific hypervigilance and spatial attention in early visual perception. Soc. Cogn. Affect. Neurosci. 9, 723-729. doi: 10.1093/scan/ nst044
Wilson, E. J., MacLeod, C., Mathews, A., and Rutherford, E. M. (2006). The causal role of interpretive bias in anxiety reactivity. J. Abnorm. Psychol. 115:103. doi: 10.1037/0021-843X.115.1.103

Woolrich, M. W., Ripley, B. D., Brady, M., and Smith, S. M. (2001). Temporal autocorrelation in univariate linear modeling of FMRI data. Neuroimage 14:1370. doi: 10.1006/nimg.2001.0931

Conflict of Interest Statement: The authors declare that the research was conducted in the absence of any commercial or financial relationships that could be construed as a potential conflict of interest.

Copyright (c) 2016 Visser, Haver, Zwitser, Scholte and Kindt. This is an open-access article distributed under the terms of the Creative Commons Attribution License (CC BY). The use, distribution or reproduction in other forums is permitted, provided the original author(s) or licensor are credited and that the original publication in this journal is cited, in accordance with accepted academic practice. No use, distribution or reproduction is permitted which does not comply with these terms. 